\title{
Wind-induced vibration performance of early Chinese hall-style timber buildings
}

Yidan Han, Qing Chun* and Hui Jin

\begin{abstract}
Traditional Chinese timber buildings are lightweight, flexible, and quite vulnerable to wind. This paper aims to present a methodology for evaluating the wind-induced vibration performance of early Chinese hall-style timber buildings based on numerical simulations. First, the architectural and structural characteristics of early Chinese hall-style timber buildings were presented and analyzed. It is found that the main hall of the Tianning Temple can be considered a representative to carry out the research. Second, the wind pressure coefficients of the main hall were determined via computational fluid dynamics (CFD) simulation. Finally, the time-series wind pressures were generated, and the wind-induced vibration performance was analyzed by the finite-element method (FEM). The CFD simulation results show that the eave corners bear the maximum wind suction, and the windward pediment bears the maximum wind pressure. The FEM analysis has revealed that the lateral structural stiffness in the depth direction is smaller. Under the depth-direction wind load, most of the large displacement occurs intensively at the middle part of the windward frames. The structural response is dominated mainly by the top three vibration modes. The time-series wind vibration coefficients are larger than the code values by a factor of 1.39-1.82. This study can provide a reference for evaluating the wind-induced vibration performance of early Chinese hall-style timber buildings.
\end{abstract}

Keywords: Wind-induced vibration performance, Early Chinese timber building, Hall-style structure, Wind pressure coefficient, Wind vibration coefficient

\section{Introduction}

A large number of examples of traditional timber architecture are found in China. These structures are widespread around the country and once served as palaces, temples, ancestral halls, offices and dwellings. Most of the existing architectural heritage in China is timber buildings. Statistically, 2162 major historical and cultural sites are protected at the national level in China, 1513 of which are traditional timber buildings, accounting for $70 \%$ [1]. In addition, among all 37 UNESCO World Cultural Heritage sites in China, 16 are closely related to timber buildings [2]. Traditional timber buildings play a vital role in the architectural history of China and notably differ from traditional Western timber and masonry buildings. Under natural disasters and long-term external

\footnotetext{
*Correspondence: cqnj1979@163.com
}

School of Architecture, Southeast University, Nanjing 210096, China loads, many of these valuable timber buildings have degraded. Traditional timber buildings are lightweight and flexible and have weak resistance to lateral external forces. It is common to find traditional timber buildings damaged under strong wind actions. In 2006, one ancient temple and nine ancient timber lounge bridges in Zhejiang Province were seriously damaged in Super Typhoon Saomai. In 2016, many traditional timber buildings in Honglincuo, Fujian Province, were also damaged in Super Typhoon Nepartak, and four old timber lounge bridges collapsed in Super Typhoon Meranti. In 2019, many timber buildings on an ancient street in Wenling, Zhejiang Province, suffered severely in Super Typhoon Lekima. All the above-mentioned damage happened in the southeastern coastal area, where many traditional timber buildings are distributed. Therefore, the accurate evaluation of the wind-resistance performance is an important issue for the scientific conservation of traditional timber buildings. 
Traditional Chinese timber buildings are impressive due to their giant roof shapes with elegant designs and exquisite craftsmanship. In addition to the common double-pitch roof and the hip roof, there are also multiple styles of complicated roof configurations, such as the nine-edge roof and double-eave roof. These featured roof styles subsequently lead to the wind sensitivity of timber buildings. At present, research focusing on the wind pressure on buildings and the wind-resistance performance of traditional timber buildings is very limited. A general review of the related literature in China is presented. Wu et al. [3] conducted a wind tunnel experiment on an archaized timber pagoda, and the wind pressure coefficients applicable for the pagoda were proposed. $\mathrm{Li}$ et al. [4] performed a wind vibration calculation for the Yingxian Timber Pagoda with the mode analysis method and obtained wind vibration coefficients for the pagoda. An FEM analysis of the main hall of the Baoguo Temple was carried out by Han and Chun [5], and the dynamic and static behavior of the main hall was compared and discussed. Liu [6] simulated the wind field around the Hall of Supreme Harmony built in the Qing Dynasty with different wind velocities and directions and obtained the wind pressure coefficients of the roof. Similar work was also performed by Yang [7] on an archaized timber building with the style of the Tang Dynasty, and reference values of the wind pressure coefficients were proposed.

Outside China, there are also some researchers with interest in the wind-resistance performance of timber buildings. Hanazato et al. [8] introduced a new monitoring technique for the long-term wind-induced response of the five-storied pagoda, which is one of the most important architectural timber structures in Japan. Zisis [9] studied the wind-induced vibration performance of residential timber buildings normally seen in North America with experimental and numerical methods. Malone et al. [10] established an FEM of a local timber building with pinned connection joints with the software SAP2000 (Structural Analysis Program 2000) and achieved force-transferring paths under wind action. In the study presented by Morrison [11], particular attention was given to the failure modes of a low-rise building during a wind tunnel test. He et al. [12] proposed an FEM analysis method for evaluating the mechanical behavior of the whole structure and the connection performance of members in a lightweight timber frame building under wind load. Alireza and Sarkar [13] carried out a reducedscale model experiment of a double-pitch roof timber building in a tornado field, and they explored the influence of building parameters on the wind pressure distribution. Singh and Roy [14] used Fluent to simulate the wind flow field of low-rise and hip roof buildings and obtained roof wind pressure coefficients with various roof shapes and in wind directions. Roy et al. [15] simulated the wind field of a pyramid-roof pentagonal building using Fluent, and they also discussed the wind field characteristics and the wind pressure coefficients under different wind directions.

In summary, foreign studies have focused mainly on local timber buildings, whose architectural forms, material properties, joint connection methods and structural characteristics are quite distinct from those of traditional Chinese timber buildings. Moreover, Chinese studies have generally aimed at the wind-induced vibration of high-rise timber buildings such as pagodas or low-rise buildings with regular roof styles. Regarding the structural conservation of traditional Chinese timber buildings, there is no mature standard or guideline. Scarce references for wind-resistance studies also limit the scientific practice of renovation or preventive protection. In this paper, the wind-induced vibration performance of early Chinese hall-style timber buildings is systematically studied in detail. The architectural and structural characteristics of early Chinese hall-style timber buildings are presented, and the wind pressure coefficients of a hallstyle timber building were determined via CFD simulation. Then, time-series wind pressures are generated, and the wind-induced vibration performance of the building is analyzed by FEM.

\section{Early Chinese hall-style timber buildings}

\section{Architectural and structural characteristics}

The earliest timber building existing in China was built in the Tang Dynasty (A.D. 618-907), but the number of existing buildings of the Tang Dynasty is quite small. Timber buildings built in the Song and Yuan Dynasties (A.D. 960-1368) account for a large proportion of the existing traditional timber buildings, of which hall-style buildings make up the main part. In the old book Ying $\mathrm{Zao} \mathrm{Fa}$ Shi written by the well-known architect Li Jie in the Song Dynasty, there are 19 drawings of hall-style buildings, implying the importance of this structural style. Two examples of hall-style buildings are shown in Fig. 1. The main characteristic of the hall style is that inner columns are obviously taller than outer columns; thus, it provides a higher central space for worship. Dingtougong, a type of connection of beam and column, is widely used in hall-style buildings and contributes to good structural integrity. In this study, six early Chinese hall-style buildings were chosen to investigate the architectural and structural characteristics. The plane layout and dimensions are shown in Fig. 2 and Table 1, respectively.

According to Fig. 2 and Table 1, the plane layout of the hall-style building is basically square, and the building height is slightly smaller than the width. The ratio of 


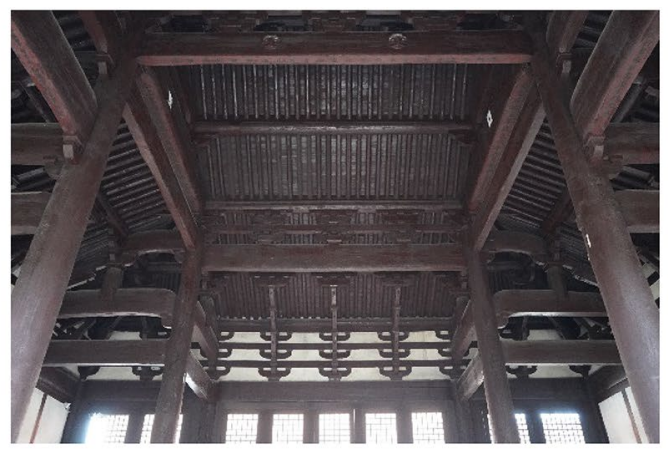

a The main hall of the Tianning Temple

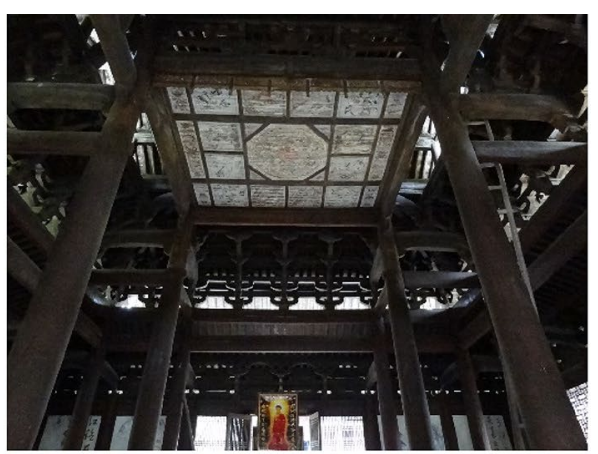

b The main hall of the Yanfu Temple

Fig. 1 Typical early hall-style timber buildings

the building length to the width is $0.836-1.120$, and the ratio of the building height to the width is 0.728-1.024. There are generally three bays in the width direction, and the middle bay is wider than the other two bays. In the depth direction, it is also three bays deep, and the first and second bays are wider than the last bay. Based on the analysis above, we can consider that the main hall of the Tianning Temple is a typical early hall-style timber building, and it can be used to study the wind-induced vibration performance of early Chinese hall-style timber buildings.

\section{Information of the main hall of the Tianning Temple}

The main hall of the Tianning Temple is a square building with both a depth and width of $12.72 \mathrm{~m}$, a total height of $11.5 \mathrm{~m}$ and an eave bottom height of $6.1 \mathrm{~m}$. The diameter of the columns is approximately $450 \mathrm{~mm}$. The inside and outside appearances of the main hall are shown in Fig. 3. To obtain accurate geometrical information, precise scanning is carried out with a 3D laser scanner, Leica Scan Station P16 scanner, which has a maximum scanning distance of $80 \mathrm{~m}$ and a point position error of $5 \mathrm{~mm} / 80 \mathrm{~m}$ and has a $360^{\circ}$ panoramic view and a superfast scanning speed of 1 million points per second. The 3D scanning results are shown in Fig. 4.

\section{Determination of wind pressure coefficients via CFD simulation}

To carry out the wind-resistance performance analysis, the wind load on the building surface must be determined first. The wind load is related to the basic wind pressure, terrain, ground roughness, and building height and shape. In the Chinese Load Code for the Design of Building Structures (the load code) [16], the wind pressure coefficient is introduced to describe the ratio of the actual pressure on the building to the wind pressure calculated from the wind speed. In the load code, only wind pressure coefficients of simple-shaped buildings are provided, whereas traditional buildings with relatively complicated shapes are not included. In this section, the wind pressure coefficients of the main hall of the Tianning Temple are obtained by CFD simulation with Fluent version 16.0. Before starting the simulation of the main hall, preliminary verification work is performed to determine the turbulence model suitable for the case.

\section{Verification of the turbulence model}

The large eddy simulation (LES) model and Reynoldsaveraged Navier-Stokes (RANS) $k-\varepsilon$ model are the two main methodologies in practice for evaluating wind effects on buildings. The RANS method relies on a statistical description of the flow, and the $k-\varepsilon$ model provides time-averaged information of a high Reynolds number and fully turbulent flow with a relatively low computer demand. Theoretically, LES could provide a more accurate simulation relying on transient calculation and enable users to obtain the fluctuating wind loads for structural resistance design and peak wind pressure coefficients for cladding design, but LES requires an increased computational cost by a factor of more than 80 [17]. Out of consideration for the computational cost, the RANS model is a better choice if users care more about the fully developed steady flow rather than the transient changes. Thus, the mean wind pressure coefficients could be assessed using the steady-state RANS model at the significantly reduced cost of computational resources.

Today, in practical applications, the RANS model has been widely used to evaluate the mean wind pressure distribution on a building. The simulation results of the RANS model have been found to be in good agreement with the wind tunnel tests [17-21]. Here, three RANS models (the shear stress transfer (SST) k- $\varepsilon$ model, the 


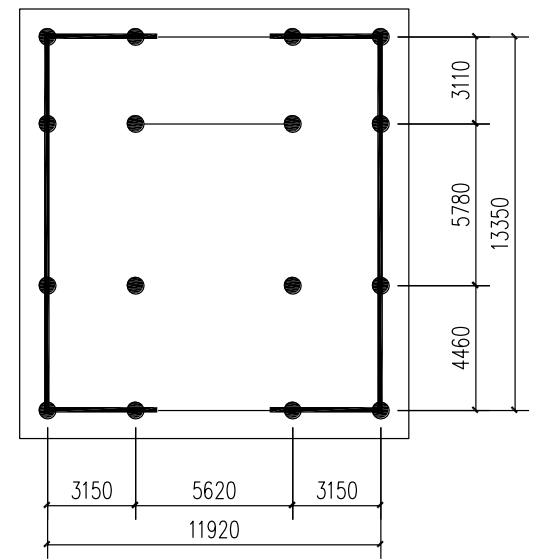

a Main hall of the Baoguo Temple

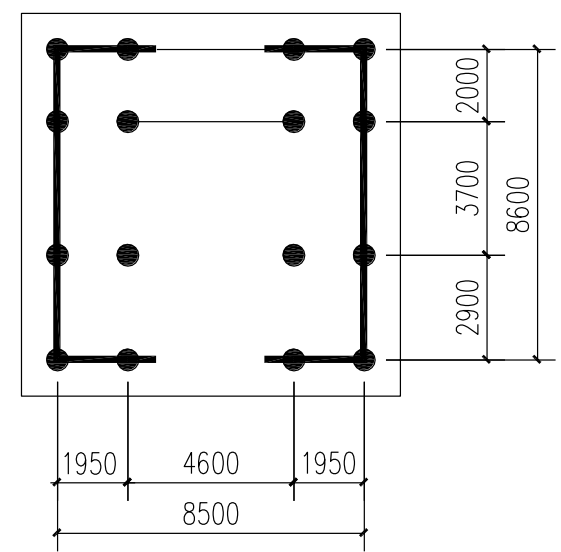

c Main hall of the Yanfu Temple

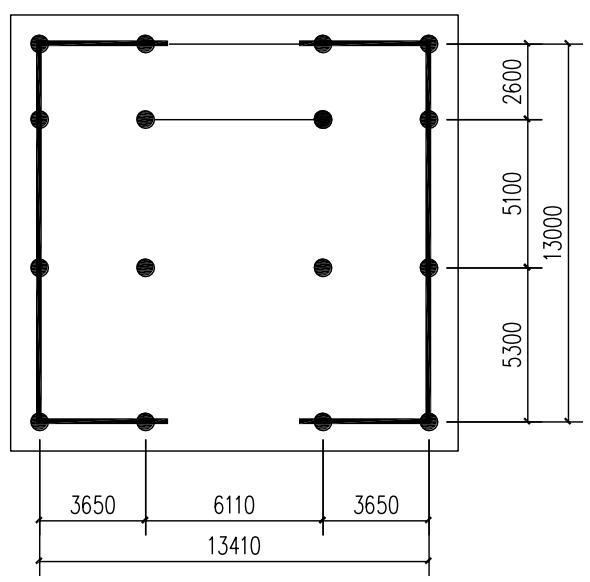

e Main hall of the Zhenru Temple

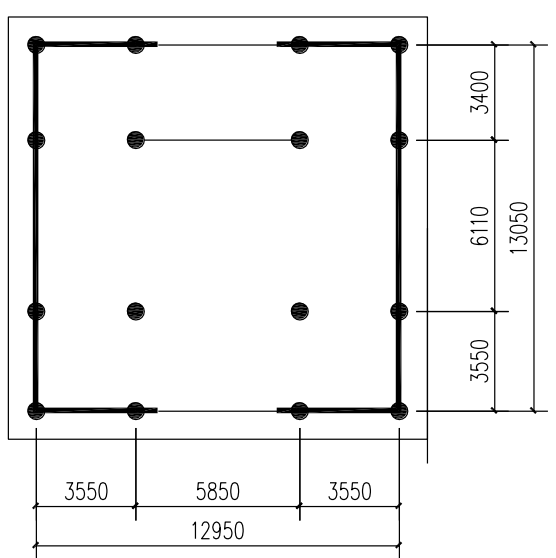

b Main hall of the Baosheng Temple

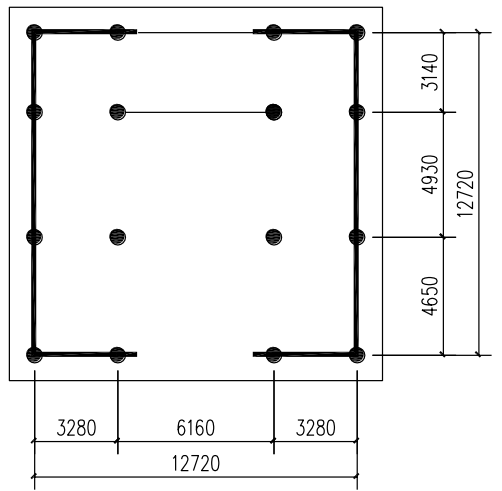

d Main hall of the Tianning Temple

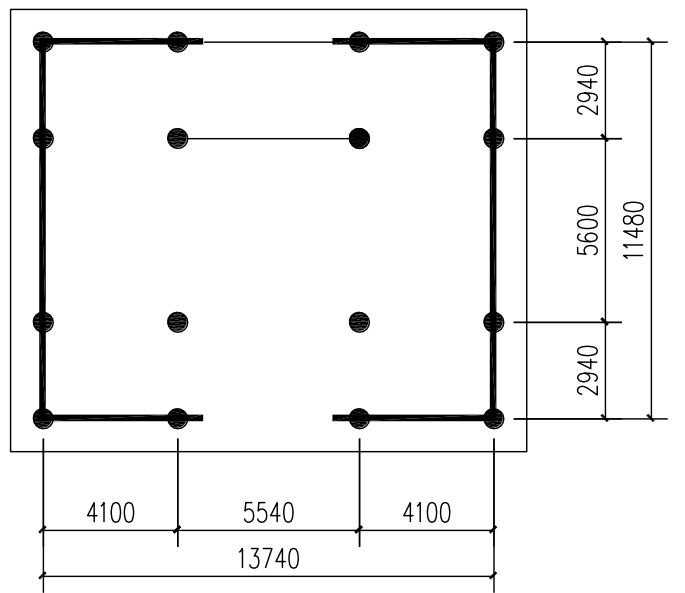

f Main hall of the Xuanyuan Palace

Fig. 2 Plane layout of the six hall-style buildings (mm) 
Table 1 Plane dimensions of the six hall-style buildings

\begin{tabular}{|c|c|c|c|c|c|c|}
\hline No & Name & Location & $\begin{array}{l}\text { Building time } \\
\text { (A.D.) }\end{array}$ & Structure & $\begin{array}{l}\text { Ratio of the length } \\
\text { to the width }\end{array}$ & $\begin{array}{l}\text { Ratio } \\
\text { of the height } \\
\text { to the width }\end{array}$ \\
\hline 1 & Main hall of the Baoguo Temple & Ningbo/Zhejiang & 1013 & Hall style & 1.120 & 0.897 \\
\hline 2 & Main hall of the Baosheng Temple & Suzhou/Jiangsu & 1073 & Hall style & 1.008 & 0.775 \\
\hline 3 & Main hall of the Yanfu Temple & Wuyi/Zhejiang & 1317 & Hall style & 1.012 & 1.024 \\
\hline 4 & Main hall of the Tianning Temple & Jinhua/Zhejiang & 1318 & Hall style & 1.000 & 0.904 \\
\hline 5 & Main hall of the Zhenru Temple & Shanghai & 1320 & Hall style & 0.969 & 0.856 \\
\hline 6 & Main hall of the Xuanyuan Palace & Suzhou/ Jiangsu & 1369 & Hall style & 0.836 & 0.728 \\
\hline
\end{tabular}

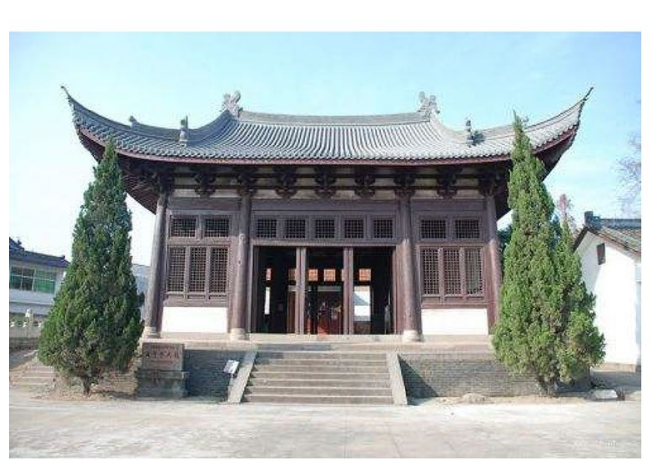

a Outside appearance

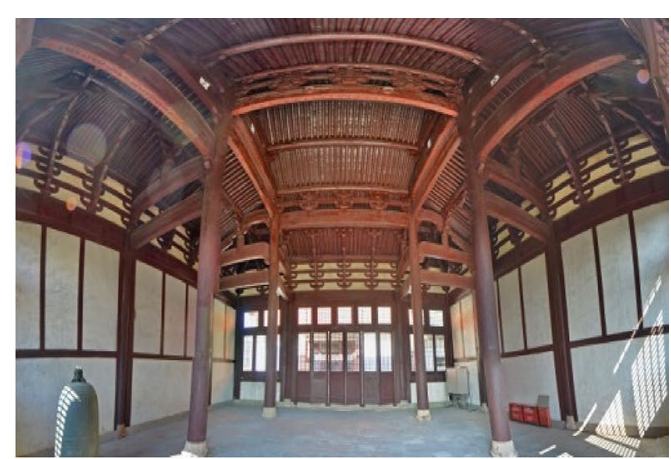

b Inside appearance

Fig. 3 Main hall of the Tianning Temple

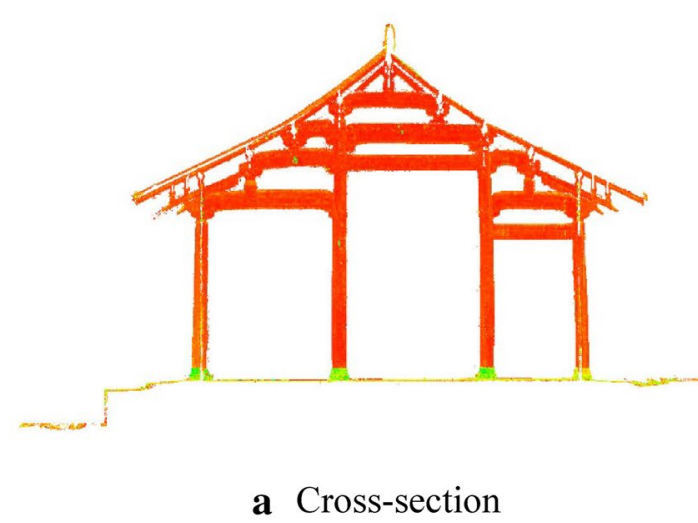

Fig. 4 3D scanning cloud images of the main hall

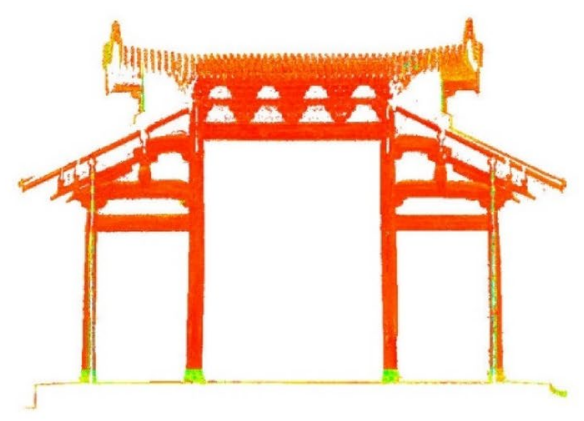

b Longitudinal section

renormalization group (RNG) $\mathrm{k}-\varepsilon$ model, and the standard $\mathrm{k}-\varepsilon$ model) are used to simulate the wind field of a double-pitch roof low-rise building. The simulated wind pressure coefficients are compared with the values suggested by the load code to verify the feasibility of the simulation method and to determine which model is more suitable for the simulation of the main hall.

\section{Verification: computational domain and boundary conditions}

The building models are created with the same shape dimensions and roof pitch as the main hall. The computational domain dimensions are selected according to the best practice guidelines of the wind CFD simulation proposed by Franke et al. [22] and Tominaga et al. [23]. The 
upstream length must be larger than five times the building height and one-third of the whole wind domain length. The blockage rate must be less than $3 \%$ to guarantee that the wind around the building can fully develop. The resulting domain dimensions are chosen as $240 \mathrm{~m} \times 140 \mathrm{~m} \times 100 \mathrm{~m}$, which can meet all the above requirements. The building model is placed $80 \mathrm{~m}$ away from the wind inlet surface.

The wind domain is divided into three parts (Fig. 5) to simultaneously use the structured and unstructured mesh (Fig. 6). The unstructured mesh (tetrahedral and prism elements) is adopted in the middle part where the building is located because the unstructured mesh adapts better to the irregular shape. Two side parts are built up with the structured mesh (hexahedral elements). There are 489,351 nodes, 99,254 shell elements, and 1,484,365 volume elements in the wind domain.

The inlet boundary was set as the velocity-inlet condition, which was imported through the user-defined function (UDF) interface. The inlet boundary is described by the wind velocity, the turbulent kinetic energy $k$ and the turbulence dissipation rate $\varepsilon$. The load code gives the wind velocity expression as follows:

$$
\begin{aligned}
& u(z)=u_{0}\left(\frac{z}{z_{0}}\right)^{\alpha}, \\
& k_{z}=1.5 *(u(z) \cdot I)^{2}, \\
& I_{z}=0.1(z / 5)^{-\alpha-0.05}, \\
& \varepsilon_{z}=0.09^{0.75} \frac{k_{z}^{1.5}}{l_{z}}, \\
& l_{z}=100(z / 30)^{0.5},
\end{aligned}
$$

where $z$ is the node height; $z_{0}=10 \mathrm{~m}$ is the reference height; $u(z)$ is the wind velocity at the height of $z ; u_{0}$ is

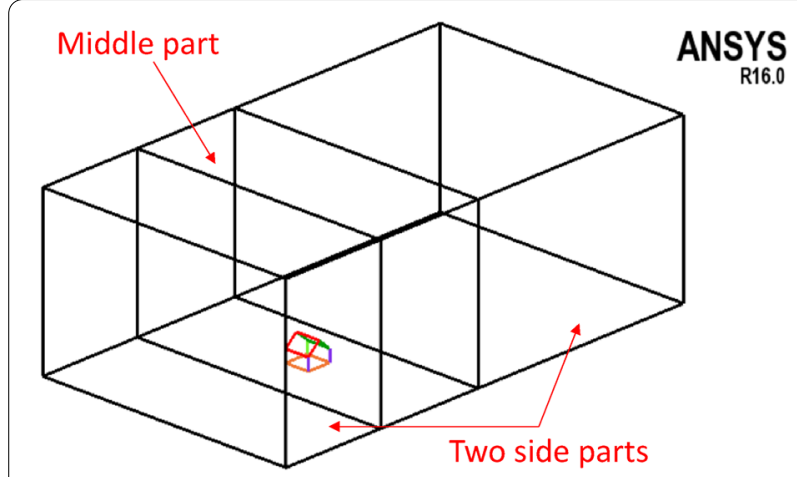

Fig. 5 Three parts of the wind domain $\left(\theta=0^{\circ}\right)$

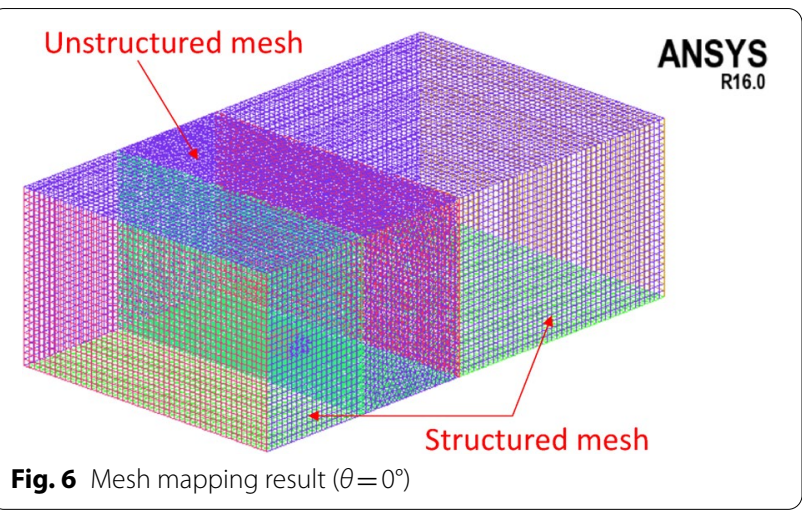

the wind velocity at the reference height; $\alpha=0.16$ is the roughness index; $I_{z}$ is the turbulence intensity; and $l_{z}$ is the turbulence integral scale. The wind velocity profile at the inlet boundary is shown below in Fig. 7 .

The outlet boundary was set as the fully developed outflow condition with zero static pressure. Standard wall conditions were applied for the building surfaces and ground surface. The two overlapping surfaces are set as the interface.

\section{Verification: results}

The results show that the RNG $k-\varepsilon$ model performed best among the three models. The wind pressure coefficient contours obtained by simulation using the RNG k- $\varepsilon$ model are shown in Fig. 8, and the comparison with the load code values is illustrated in Fig. 9 (black numbers are simulation results, red numbers are error rate). Therefore, the RNG k- $\varepsilon$ model is considered the best choice in simulating the main hall.

\section{Setup of CFD simulation of the main hall}

In the main hall of the Tianning Temple, there are clapboards between the bucket arches (Fig. 3), so the building is in an enclosed state when the doors and windows are closed. In the simulation, the state of open windows and

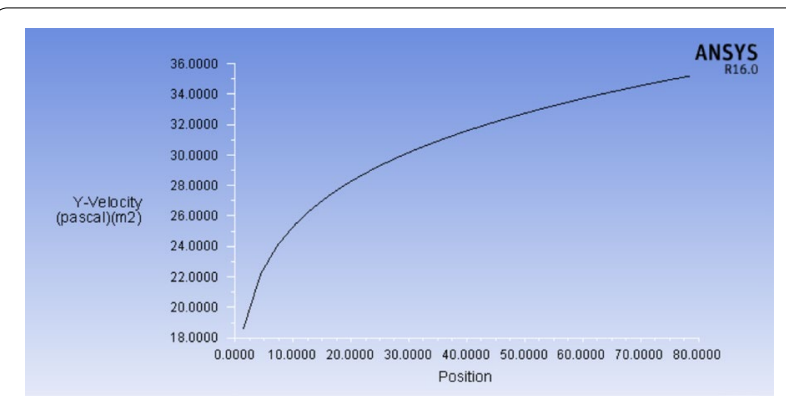

Fig. 7 Wind inlet velocity profile $(\mathrm{m} / \mathrm{s})$ 

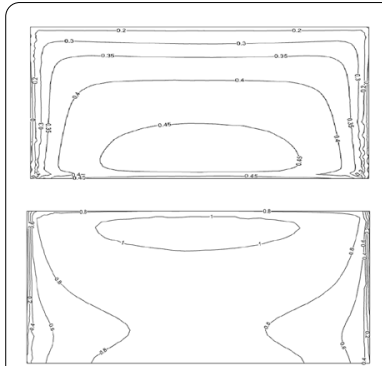

a Windward
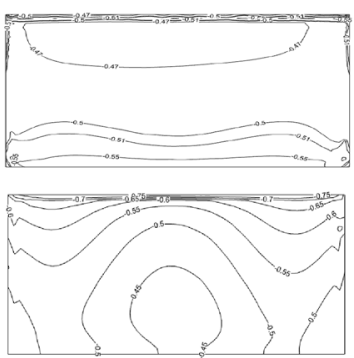

b Leeward

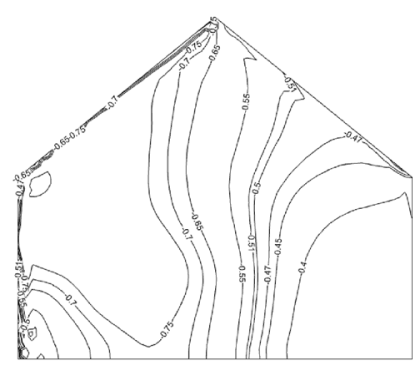

c Crosswind

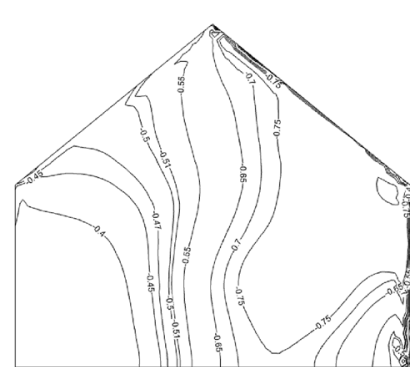

d Crosswind

Fig. 8 Wind pressure coefficient contours simulated by the RNG k- $\varepsilon$ model

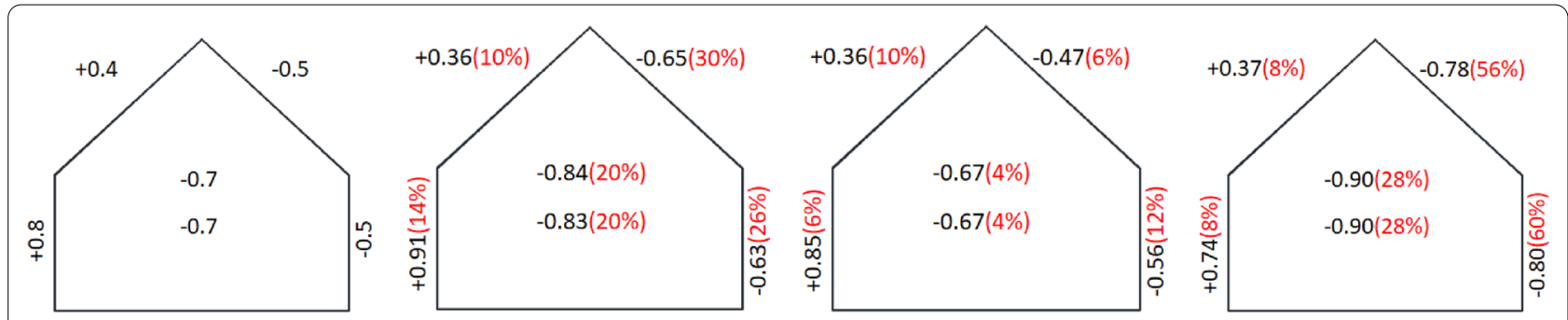

Fig. 9 Comparison of three turbulence model simulation results with the load code values

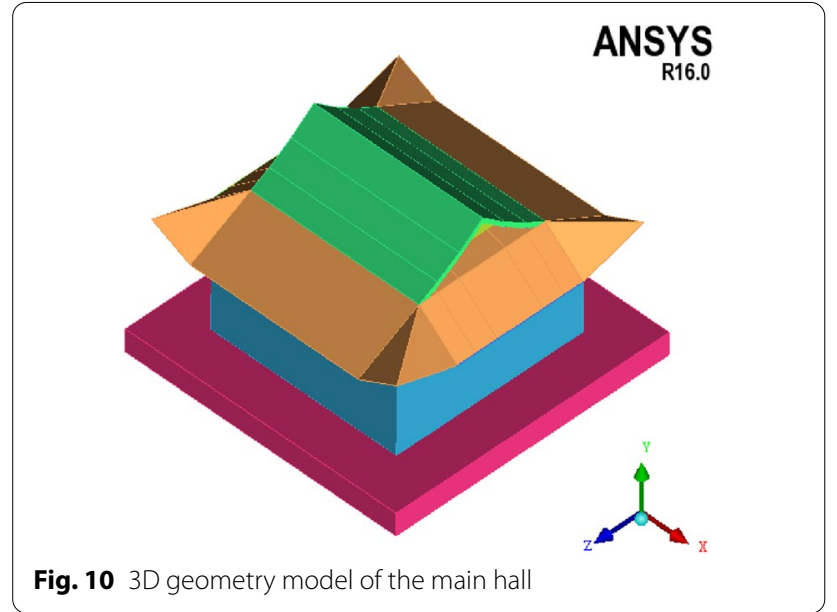

open doors is not considered in this study. The full-scale 3D model of the main hall has been established (Fig. 10).

Two orthogonal wind directions $\left(\theta=0^{\circ}\right.$ and $\left.\theta=90^{\circ}\right)$ were simulated. $\theta=0^{\circ}$ is the wind direction perpendicular to the building width, and $\theta=90^{\circ}$ is the wind direction perpendicular to the building depth. For both wind directions, the wind domain dimensions, boundary conditions and meshing method remain the same as those in the verification case. The final meshed wind domain contains 513,001 nodes, 102,756 shell elements, and 1,688,562 volume elements under $\theta=0^{\circ}$ and 497,161 nodes, 98,682 shell elements, and 1,490,839 volume elements under $\theta=90^{\circ}$. The mesh results $\left(\theta=0^{\circ}\right)$ are shown in Fig. 11.

\section{CFD simulation: results and discussion Wind flow streamlines}

Through the CFD simulation, the wind velocity streamlines around the main hall under the two wind directions were obtained, as shown in Fig. 12.

\section{Wind pressure coefficient distribution}

The wind pressure coefficient $C_{p i}$ at point $i$ is calculated as:

$$
C_{p i}=\frac{P_{i}-P_{0}}{0.5 \rho u_{0}^{2}}
$$

where $P_{i}$ is the wind pressure at point $i$ of the building surface; $P_{0}$ is the reference static pressure (air pressure at a height of $10 \mathrm{~m}$ ); and $\rho=1.225 \mathrm{~kg} / \mathrm{m}^{3}$, which is the air density.

To better present the results of the wind pressure coefficient distribution, all parts of the building surface are named as follows: the four roofs are named $\mathrm{R} 1 \sim \mathrm{R} 4$, the four eaves are named E1 $\sim \mathrm{E} 4$, the eight 


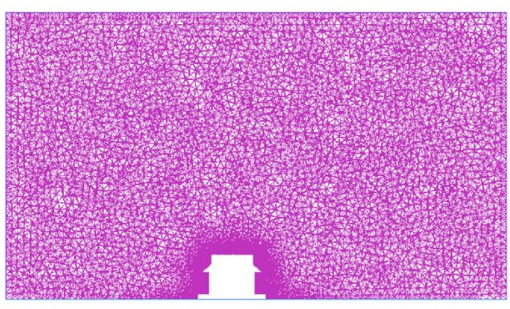

a Cross-section $(z=6.36 \mathrm{~m})$

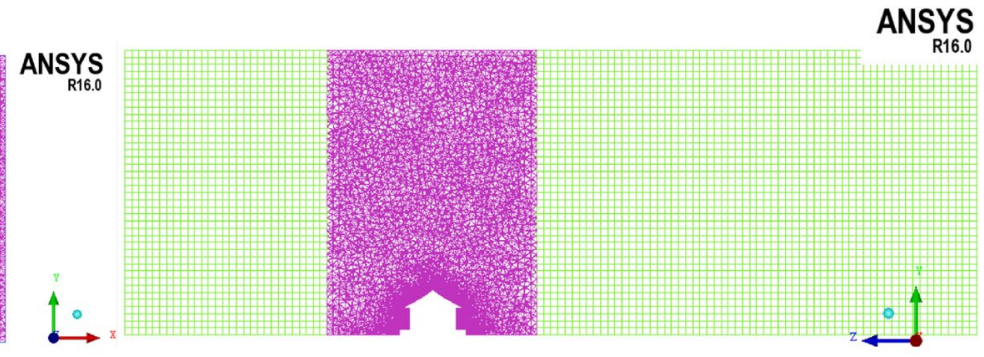

b Longitudinal section $(x=6.36 \mathrm{~m})$

Fig. 11 Mesh slices of the wind domain $\left(\theta=0^{\circ}\right)$

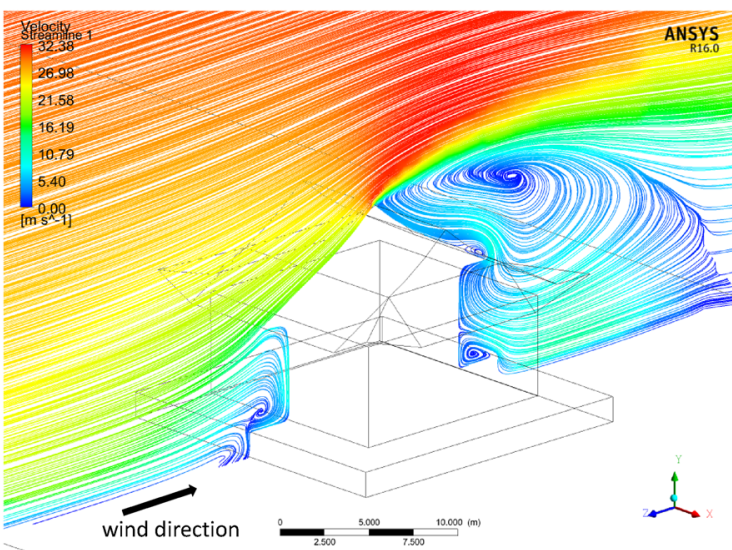

a

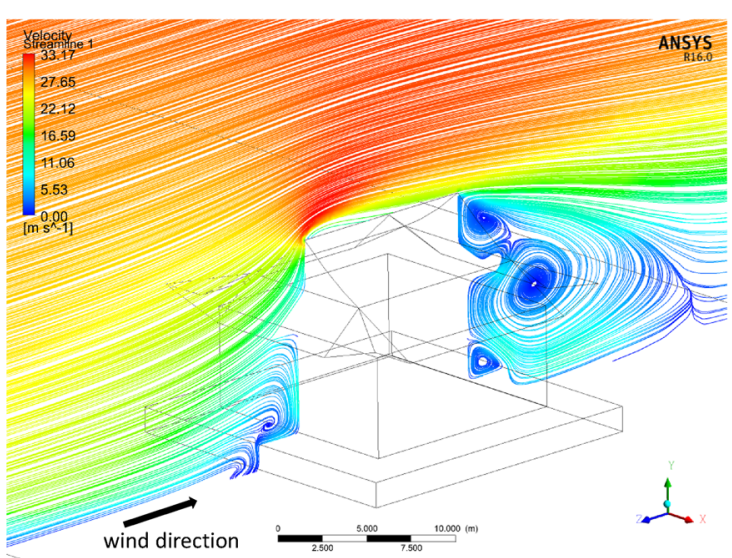

b

Fig. 12 Schematic diagrams of velocity streamlines on the longitudinal mid-planes around the building under wind direction: $\mathbf{a} \theta=0^{\circ}, \mathbf{b} \theta=90^{\circ}$

eave corners are named $\mathrm{C} 1 \sim \mathrm{C} 8$, and the four walls are named $\mathrm{W} 1 \sim \mathrm{W} 4$. The naming result is illustrated in Fig. 13.

The results of the wind pressure coefficient contours of all parts on the building surface under wind directions $\theta=0^{\circ}$ and $\theta=90^{\circ}$ can be obtained, as shown in Figs. 14 and 15 , respectively.

According to the analysis of Figs. 14 and 15, the following conclusions can be drawn:

(1) Under the two wind directions, the wind pressure coefficients are distributed symmetrically, and positive wind pressure occurs at the windward surfaces. The closer the area is to the edge, the denser the contour lines are, indicating that the change gradient of the wind pressure is larger in the area near the edges.

(2) Under the two wind directions, the wind pressures on the crosswind and leeward surfaces are basically

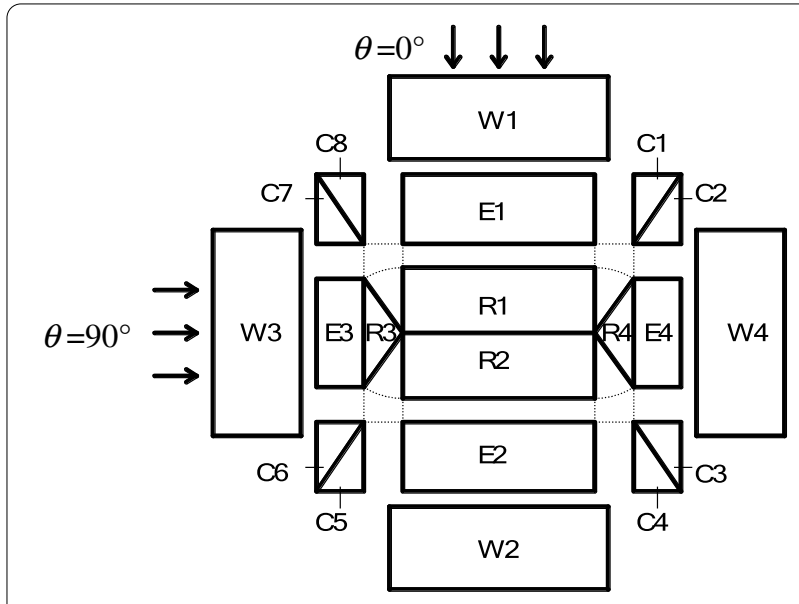

Fig. 13 Naming of all parts on the surface of the main hall 


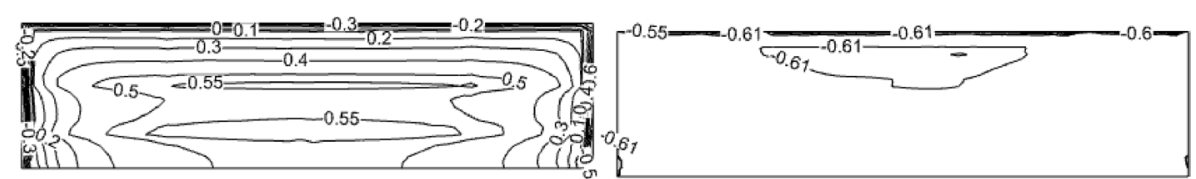

a R1

b R2
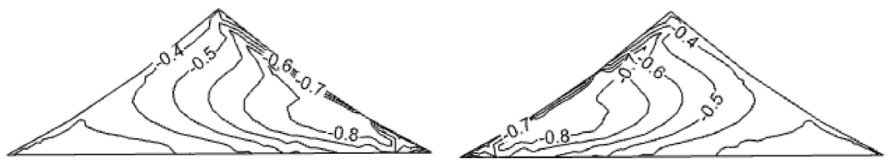

c R3

d $\mathrm{R} 4$
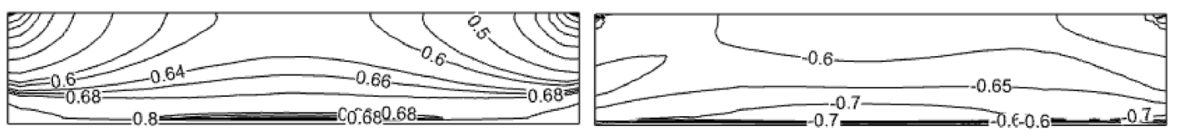

e E1

f $\mathrm{E} 2$
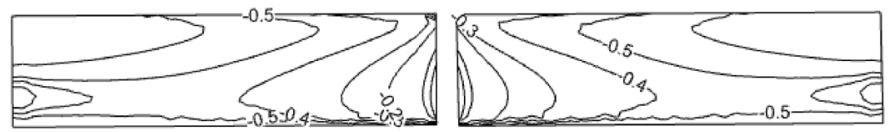

g E3

h E4
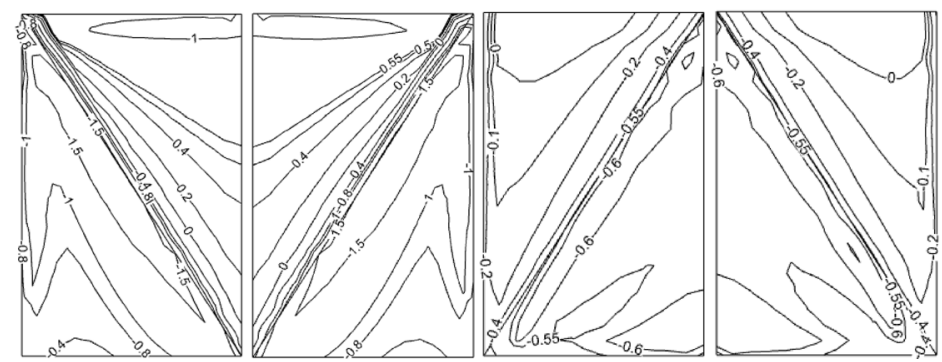

i $\mathrm{C} 7 / \mathrm{C} 8 / \mathrm{C} 1 / \mathrm{C} 2$

j $\mathrm{C} 6 / \mathrm{C} 5 / \mathrm{C} 4 / \mathrm{C} 3$

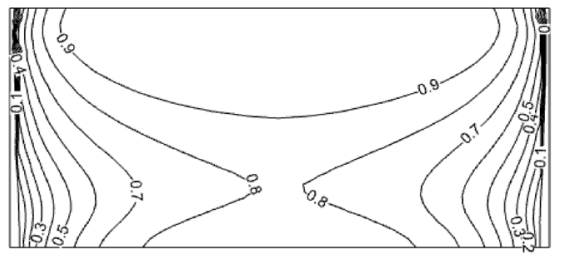

k W1

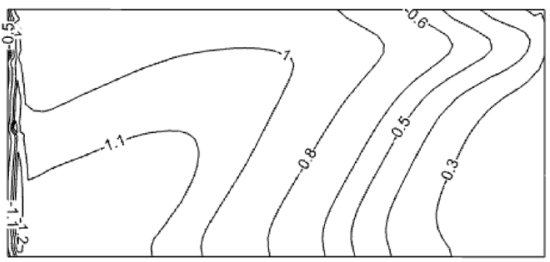

m W3

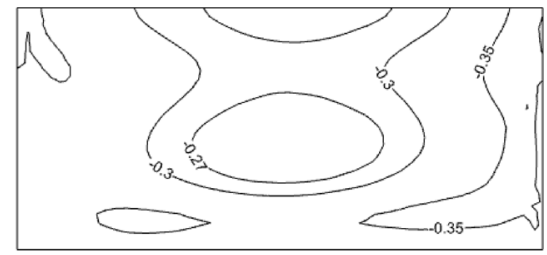

l W2

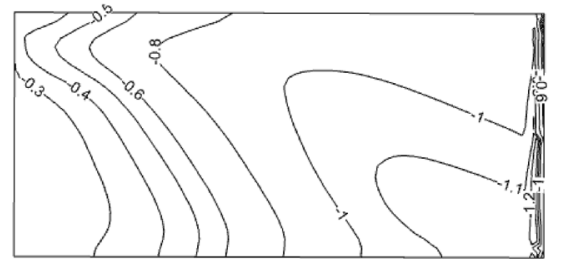

n W4

Fig. 14 Wind pressure coefficient contours of the building surface $\left(\theta=0^{\circ}\right)$ 


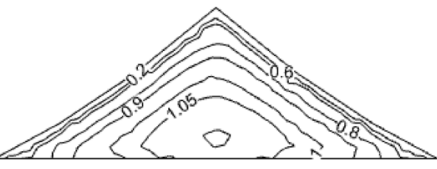

a R3

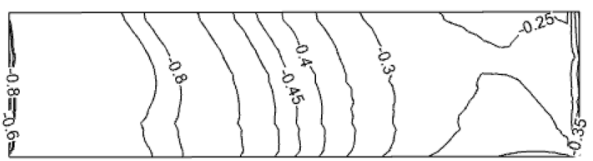

c R1

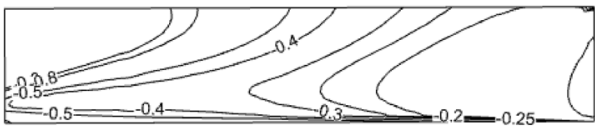

e E1

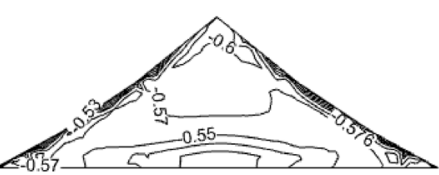

b R4

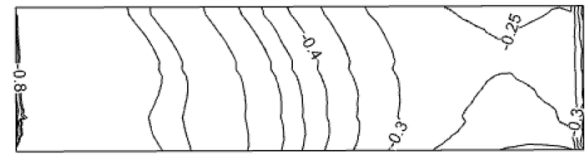

d R2

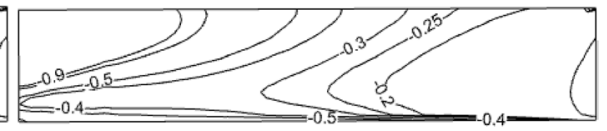

f $\mathrm{E} 2$

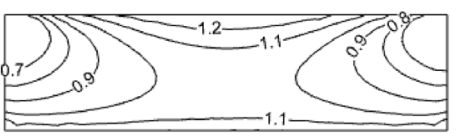

g E3

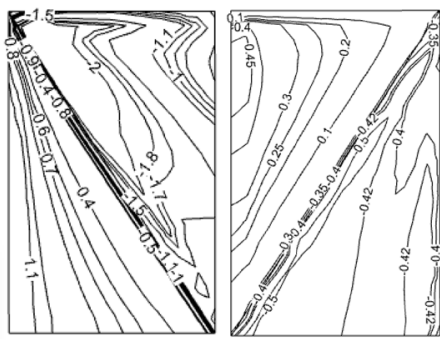

i $\mathrm{C} 7 / \mathrm{C} 8 / \mathrm{C} 1 / \mathrm{C} 2$

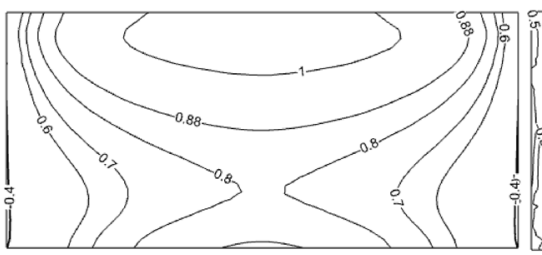

k W3

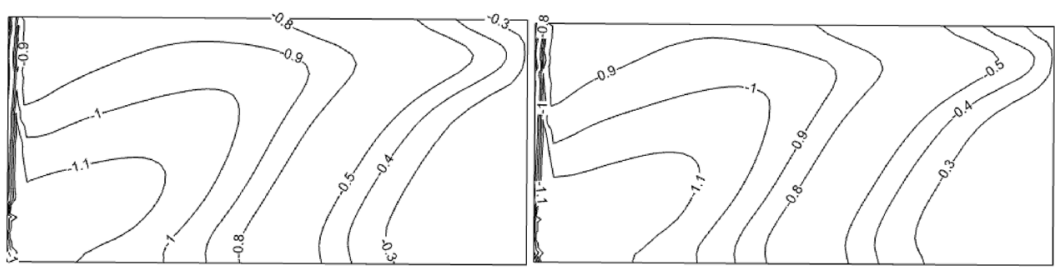

m W1

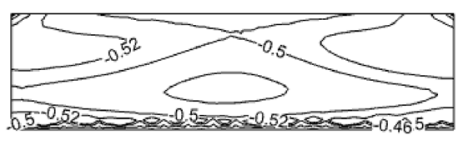

h E4

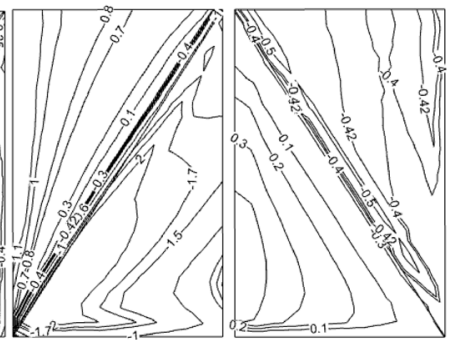

j $\mathrm{C} 6 / \mathrm{C} 5 / \mathrm{C} 4 / \mathrm{C} 3$

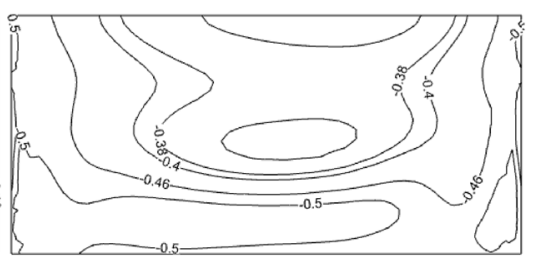

I W4

n W2

Fig. 15 Wind pressure coefficient contours of the building surface $\left(\theta=90^{\circ}\right)$ 
negative, and the absolute values of the negative pressure coefficients are all smaller than 1.

(3) Under the two wind directions, the maximum negative wind pressure occurs at the eave corners, and the coefficient is larger than 2, which means that the eave corners bear a very large wind suction. This large wind suction is also an important explanation for why the corner beams of early Chinese hall-style timber buildings are designed to be very strong.

(4) The maximum positive wind pressure coefficient occurs at the central area of the windward pediment when $\theta=90^{\circ}$. The coefficients are generally larger than 1 . These values also explain why, in most important gable-and-hip roof timber buildings built since the Song Dynasty, there is always a timber wind deflector set in front of the pediment for buffering the intense wind impact.

\section{The average wind pressure coefficients}

The average wind pressure coefficient $C_{p}$ of each part of the building surface is computed as:

$$
C_{p}=\sum\left[\frac{C_{p i} A_{i}}{A}\right],
$$

where $A_{i}$ is the surface area of point $i$, and $A$ is the overall area of the part where point $i$ is located. The average wind pressure coefficients under the two wind directions are calculated. The results are illustrated in Fig. 16.

\section{FEM analysis of the wind vibration performance Modeling}

SAP2000 was used to perform the FEM analysis. SAP2000 is a powerful software for analyzing the structural performance of spatial truss structures. The structure of the main hall of the Tianning Temple can be considered the spatial truss. The structural members of the main hall are composed mainly of columns, beams, purlins, bucket arches (also called 'dougongs'), and rafters. All the members are connected by mortise-tenon joints. There are two main types of mortise-tenon joints in this structure. As shown in Fig. 17, one type is the 'through mortise-tenon joint' connecting straight beams and columns, and the other type is the 'Dingtougong mortise-tenon joint' connecting crescent beams and columns. The Dingtougong joint is one of the obvious characteristics of hall-style buildings, which appears in all the drawings of the hall-style buildings in the book Ying $\mathrm{Zao} \mathrm{Fa}$ Shi. Dingtougong reduces the beam span to some extent and enhances the shear and flexural capacity of the joint. The distribution of the two types of joints is shown in Fig. 18.

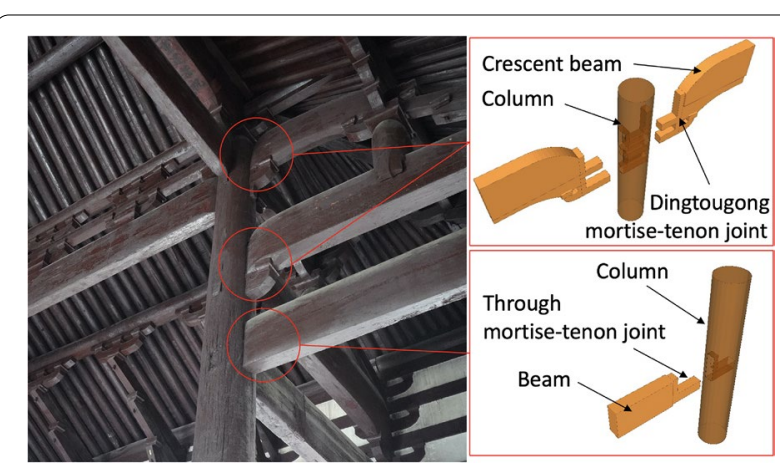

Fig. 17 Two main types of mortise-tenon joints of the main hall of the Tianning Temple

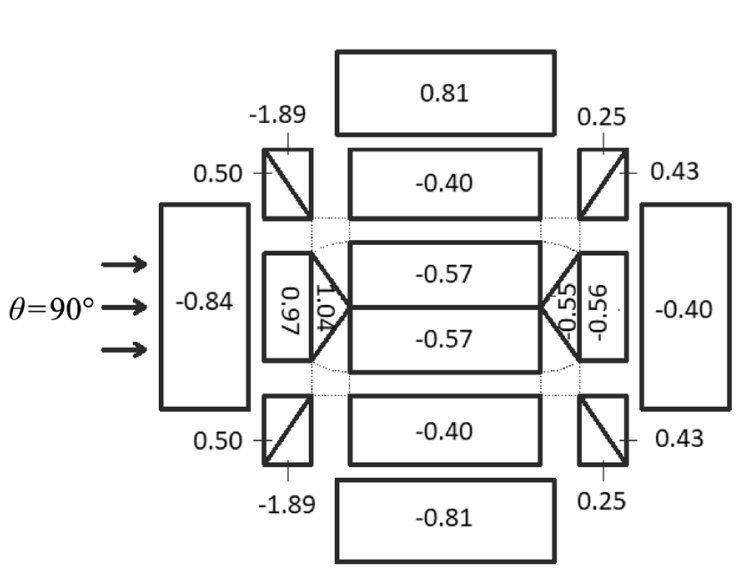

a

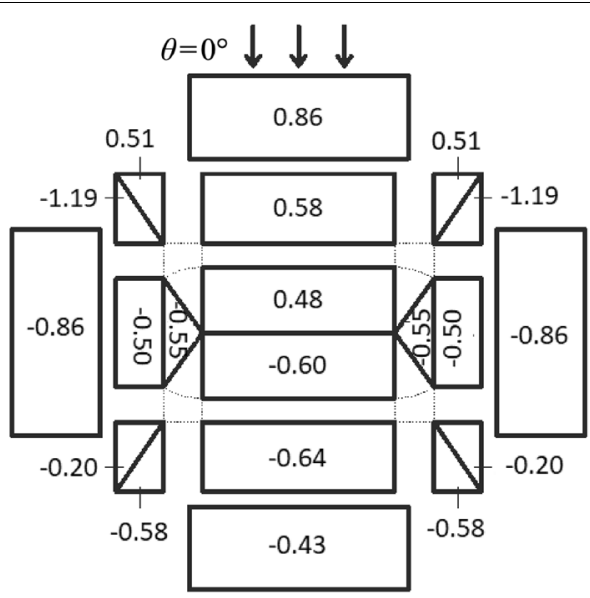

b

Fig. 16 Average wind pressure coefficients under wind directions: $\mathbf{a} \theta=0^{\circ}, \mathbf{b} \theta=90^{\circ}$ 


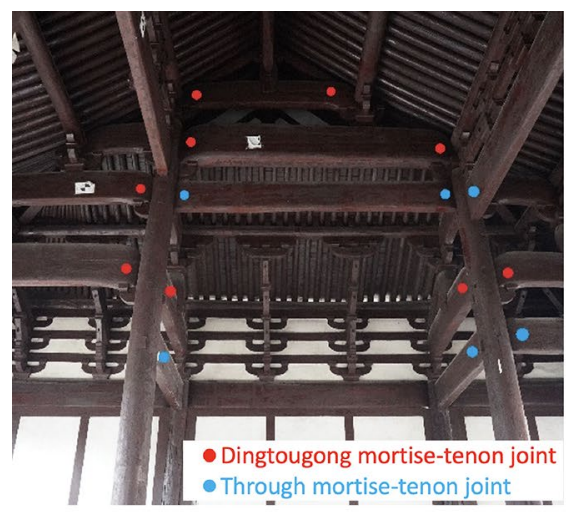

a View from the longitudinal direction

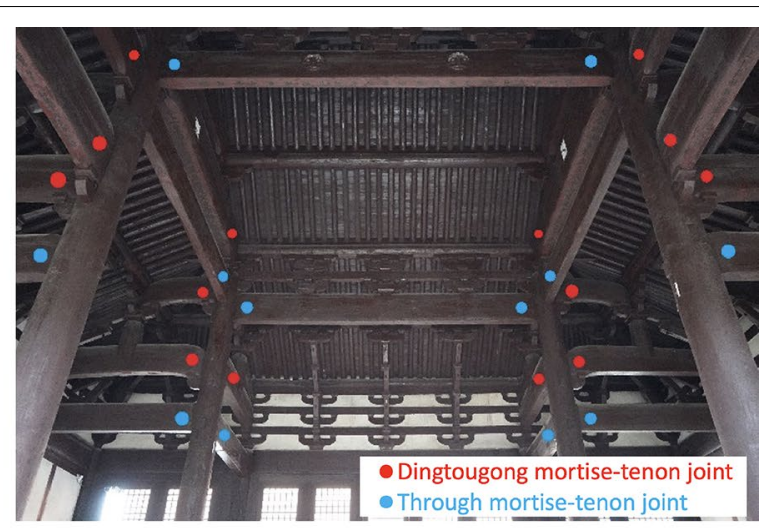

b View from the transversal direction

Fig. 18 Distribution of the two types of mortise-tenon joints

In previous studies conducted by Chun [24, 25], reduced-scale model experiments and theoretical studies on the mechanical performance of these two types of joints were carried out. The semirigidity of these two types of joints has been determined. Given the similarity principle of the reduced-scale model, the rotational rigidity of the through mortise-tenon joint is determined to be $147 \mathrm{kN} \mathrm{m} / \mathrm{rad}$, and the Dingtougong mortise-tenon joint is $350 \mathrm{kN} \mathrm{m} / \mathrm{rad}$. The bucket arch system is simulated according to a study conducted by Liu et al. [26]. They found that system internal forces transfer obliquely from the bucket to the arch under lateral external loads. They proposed a simulation method by simplifying the system to a diagonal brace and truss structure. The simulation of the bucket arch system of the main hall is performed using the same method.

According to the on-site investigation and the literature [27], the timber material of the main hall is Chinese fir. For buildings over 500 years old, the material parameters can be determined based on relative codes $[28,29]$. Reduction factors must be considered here, and the resulting parameters are as follows: the compressive strength parallel to the grain is $7.5 \mathrm{~N} / \mathrm{mm}^{2}$, the bending strength is $7.7 \mathrm{~N} / \mathrm{mm}^{2}$, the shear strength parallel to the grain is $0.84 \mathrm{~N} / \mathrm{mm}^{2}$, the elastic modulus is $6750 \mathrm{~N} / \mathrm{mm}^{2}$, and Poisson's ratio is 0.3 . There are 16 pieces of top tiles and 32 pieces of bottom tiles per square meter on the roof. The thickness of the lime layer of the roof is $12 \mathrm{~cm}$, so the calculated dead load on the roof is $3.5 \mathrm{kN} / \mathrm{mm}^{2}$. The entrance and exit walls are composed of timber lattice windows and doors; see Fig. 3a. The material of two gable walls is bamboo woven bone plastered with mud, which is the typical practice for the wall at the time [27]. The contribution of walls to the whole structural lateral stiffness is very small, so, in this study, the walls were only considered virtual surfaces to transfer wind loads. The model is finally established and shown in Fig. 19.

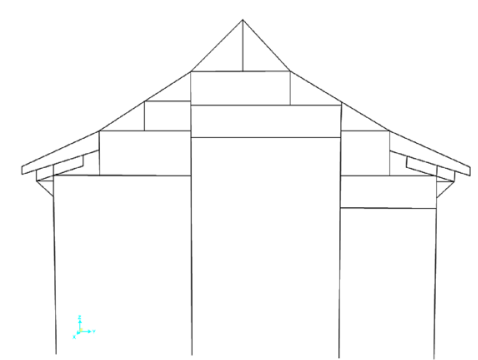

a A single frame model
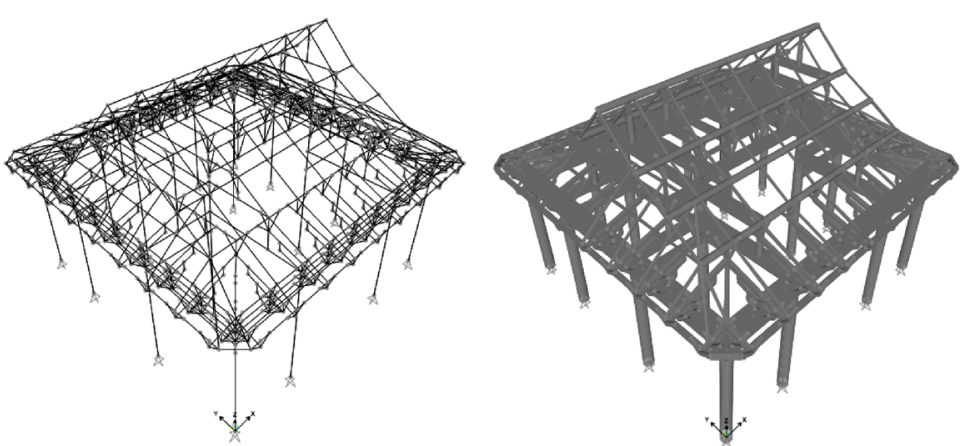

b Whole building frame model

c Model with real-sized elements

Fig. 19 Finite-element model of the main hall 


\section{Generation of wind pressure time series}

According to the literature [14, 23], the wind pressure time series $W(t)$ can be computed as:

$$
W(t)=0.5 \rho U^{2}(t)
$$

where $U(t)$ is the wind speed time series, which is regarded as the superposition of the average wind speed and the fluctuating wind speed [25]. Therefore, the wind speed time series can be expressed as:

$$
U(t)=u_{0}+u(t) .
$$

From the load code, $u_{0}=25.3 \mathrm{~m} / \mathrm{s}$ when the wind load recurrence interval is 100 years, and the building is located in Jinhua city. $u(t)$ is the fluctuating wind speed time series that can be described by the power spectrum and the correlation function [30]. The former mainly reflects the energy distribution of various frequency components in the fluctuating wind, and the latter reflects the time and space interaction of the fluctuating wind at different spatial points. They can be transformed through the Wiener-Khinchin theorem. In this study, the autoregressive (AR) model of the time-domain analysis method was used to simulate the fluctuating wind speed.

The P-dimensional AR model of the fluctuating wind speed can be described as:

$$
u(t)=-\sum_{k=1}^{P} \phi_{k} u(t-k \Delta t)+N(t)
$$

where $\phi_{k}$ is the AR coefficient matrix, $N(t)$ is a random process with a given variance, and $\Delta t$ is the time step.

There are 18 space-correlated points on the building surfaces selected for generating the wind speed time series. The 18 coordinates of all points are listed in Table 2. According to Eqs. 4 and 5, the programming of the fluctuating wind speed was executed in Matlab. A total of 18 curves of the wind speed time series at those 18 points were finally obtained. Two examples of the fluctuating wind speed time series curves are presented in Fig. 20.

\section{Results and discussion Modal analysis}

The dynamic analysis of the main hall was performed, and the top ten vibration modes are listed in Table 3 . The natural frequencies are $1.261-12.523 \mathrm{~Hz}$. The top three mode shapes of this building are shown in Fig. 21. The first is the horizontal vibration along the depth direction, the second is the horizontal vibration along the width direction, and the third is the torsional vibration. The frequency of the depth-direction vibration is slightly

\begin{tabular}{|c|c|c|c|c|c|c|c|}
\hline Coordinate & $X(\mathrm{~mm})$ & $\mathrm{Y}(\mathrm{mm})$ & $\mathrm{Z}(\mathrm{mm})$ & Coordinate & $X(\mathrm{~mm})$ & $\mathrm{Y}(\mathrm{mm})$ & $\mathrm{Z}(\mathrm{mm})$ \\
\hline 1 & 3202 & 4569 & 9364 & 10 & 6264 & 12,531 & 2635 \\
\hline 2 & 9325 & 4569 & 9364 & 11 & 1601 & 6258 & 9270 \\
\hline 3 & 3202 & 1545 & 7439 & 12 & 432 & 7861 & 7439 \\
\hline 4 & 9325 & 1545 & 7439 & 13 & 432 & 4703 & 7439 \\
\hline 5 & 6264 & 0 & 2635 & 14 & 0 & 6266 & 2635 \\
\hline 6 & 9325 & 7809 & 9364 & 15 & 10,926 & 7258 & 9270 \\
\hline 7 & 3202 & 7809 & 9364 & 16 & 12,096 & 4703 & 7439 \\
\hline 8 & 9325 & 11,019 & 7439 & 17 & 12,096 & 7861 & 7439 \\
\hline 9 & 3202 & 11,019 & 7439 & 18 & 12,527 & 6266 & 2635 \\
\hline
\end{tabular}
smaller than that of the width-direction vibration, which

Table 2 Coordinates of the space-correlated points
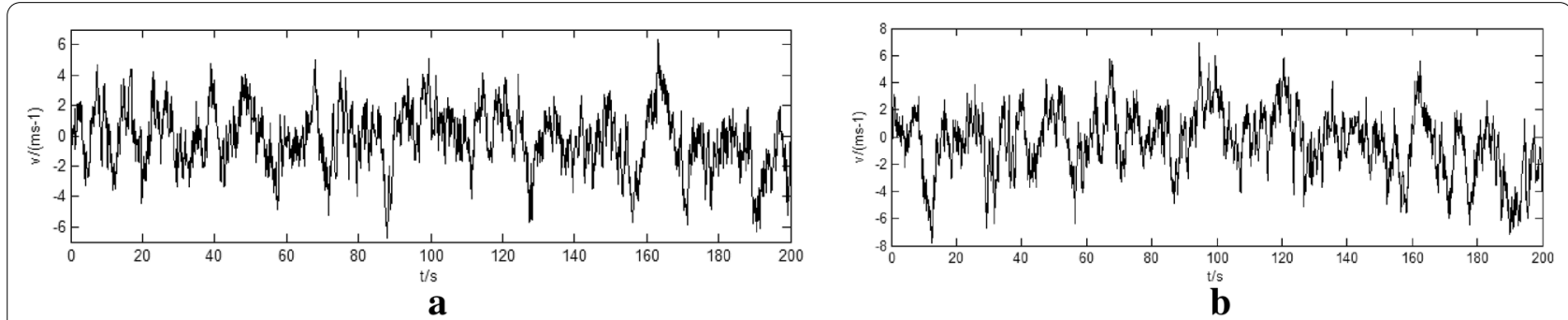

Fig. 20 Time series of the fluctuating wind speed at: a Point 3, b Point 7 
Table 3 Top ten vibration modes of the main hall

\begin{tabular}{llc}
\hline Mode & Natural period (s) & $\begin{array}{l}\text { Natural } \\
\text { frequency } \\
\mathbf{( H z )}\end{array}$ \\
\hline 1 & 0.793 & 1.261 \\
2 & 0.786 & 1.273 \\
3 & 0.706 & 1.417 \\
4 & 0.360 & 2.777 \\
5 & 0.160 & 6.261 \\
6 & 0.123 & 8.104 \\
7 & 0.120 & 8.316 \\
8 & 0.098 & 10.185 \\
9 & 0.088 & 11.382 \\
10 & 0.080 & 12.523 \\
\hline
\end{tabular}

means that the depth-direction stiffness is smaller than the width-direction stiffness.

\section{Displacement response}

As the modal analysis shows, the depth-direction stiffness is smaller. The wind pressure coefficients indicate that the general wind pressure level when $\theta=0^{\circ}$ is relatively higher than the general wind pressure level when $\theta=90^{\circ}$. In addition, the windward surface area when $\theta=0^{\circ}$ is obviously larger than the windward surface area when $\theta=90^{\circ}$, so the main hall bears larger overall wind loads if $\theta=0^{\circ}$. Therefore, in this study, only wind direction $\theta=0^{\circ}$ was executed to ensure that the most unfavorable wind-induced response is obtained. Eighteen curves of wind pressure time series generated in "Generation of wind pressure time series" section were imported into SAP2000 and applied at corresponding areas. The wind pressure coefficients were set according to the results from "The average wind pressure coefficients" section. The structural displacement response is shown in Fig. 22.

Figure 22 shows that the depth-direction displacement of the lower parts and the two side frames is relatively small, whereas the displacement of the middle frames is larger, and the maximum is $8.90 \mathrm{~mm}$. Due to the wind suction on the crosswind surfaces, the width-direction deformation is a slightly outward expansion, but it is far less than the depth-direction displacement.

Twenty-nine points on the wall and roof surfaces were chosen as the observation points for the quantitative analysis of the displacement response (Fig. 23). The displacement limitation of timber buildings is suggested to be $u_{y \max } / H=1 / 300$ [24], in which $u_{y \max }$ is the maximum displacement, and $H$ is the building height $(11,500 \mathrm{~mm})$. The computed maximum displacement is still within the allowable range. The displacement response spectrum curves of observation point N18 are shown in Fig. 24. The peak value of the displacement spectrum in the depth direction is $1.261 \mathrm{~Hz}$, which is the first natural frequency of the structure. Similarly, the two peak values of the displacement spectrum in the width direction are $1.273 \mathrm{~Hz}$ and $1.417 \mathrm{~Hz}$, which are the second and third natural frequencies. Compared with the peak values, the spectral displacements at all other frequencies are tiny. The above results indicate that the displacement response of the main hall is largely dominated by the top three vibration modes, and the vibration modes after the third contribute little to the whole structural response.

\section{Comparison between the time-series wind vibration coefficients and the code wind vibration coefficients}

The wind vibration coefficient is used to describe the impact of the fluctuating wind pressure on the structure. In the FEM analysis based on the dynamic time-series wind

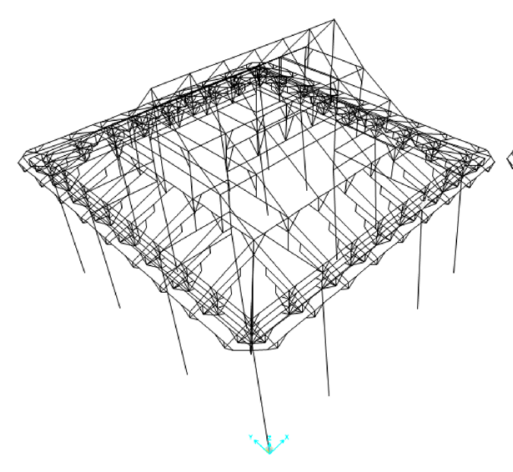

a First mode shape

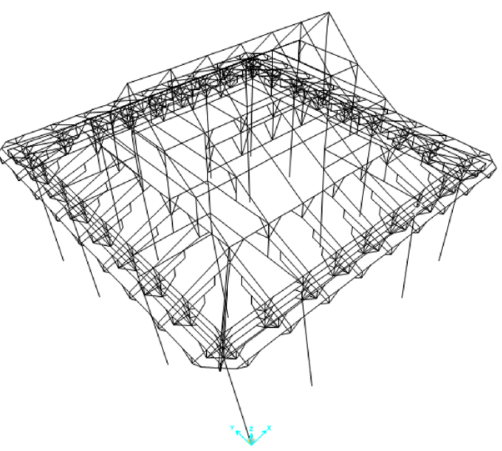

b Second mode shape

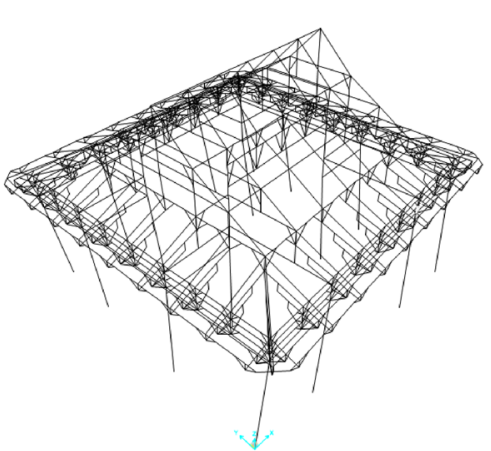

c Third mode shape

Fig. 21 Top three mode shapes of the main hall 


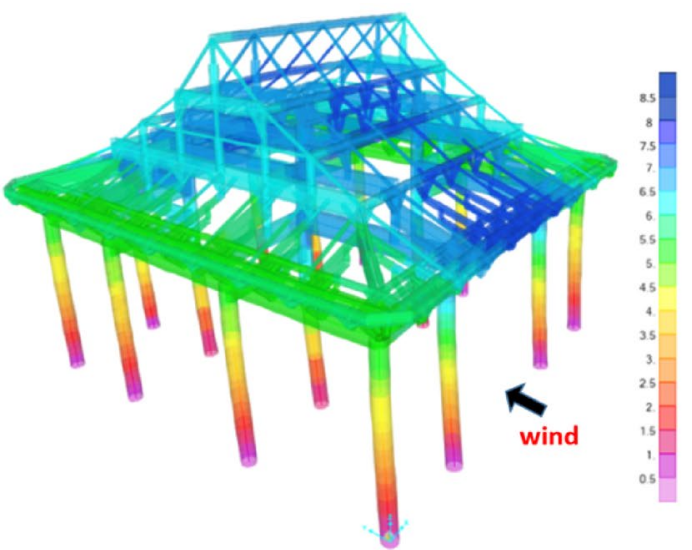

$\mathbf{a}$

Fig. 22 Displacement response of the main hall in the: $\mathbf{a}$ depth direction, $\mathbf{b}$ width direction $(\mathrm{mm})$

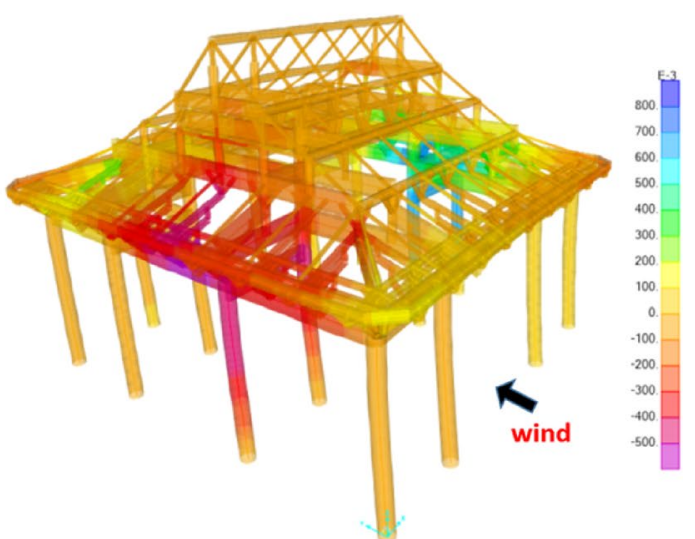

b

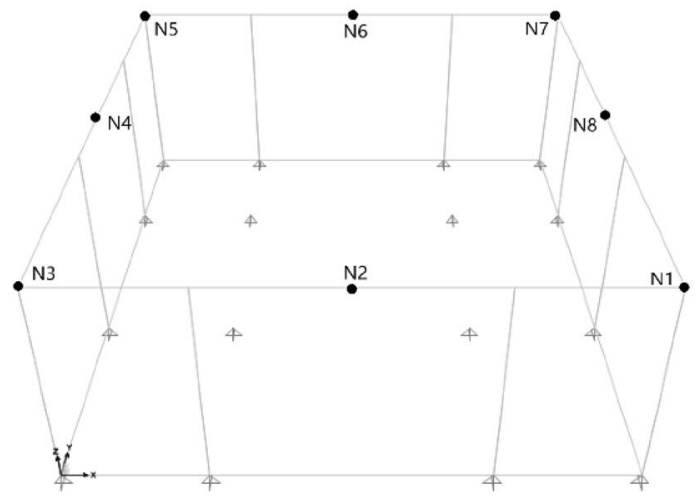

$\mathbf{a}$

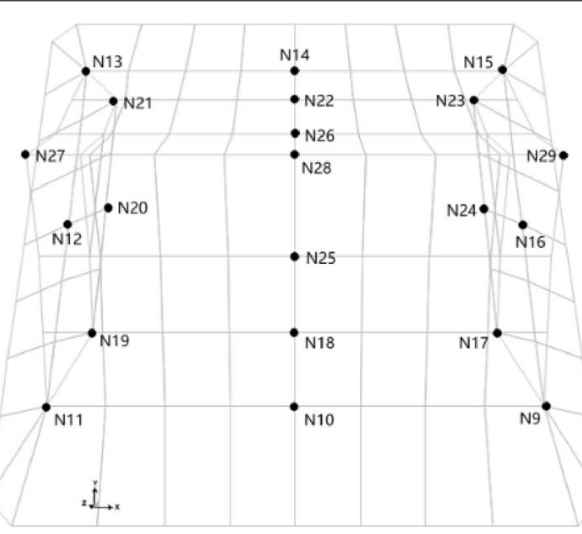

b

Fig. 23 Observation points on the: a columns and walls, b roof

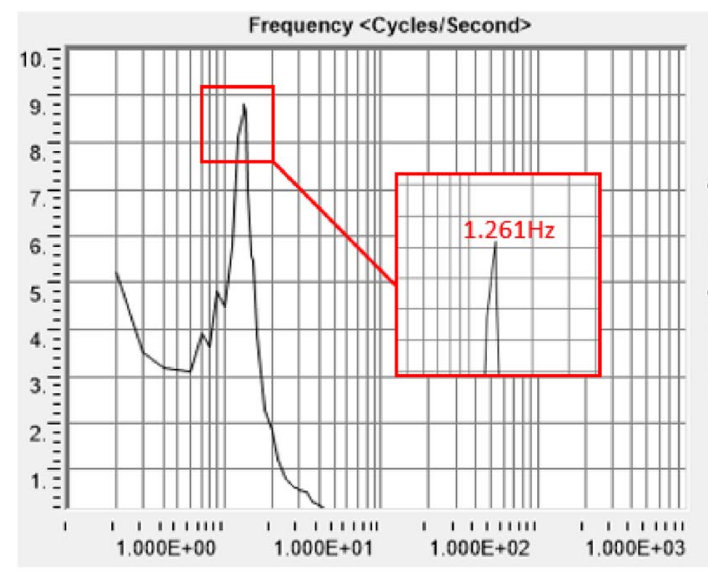

a

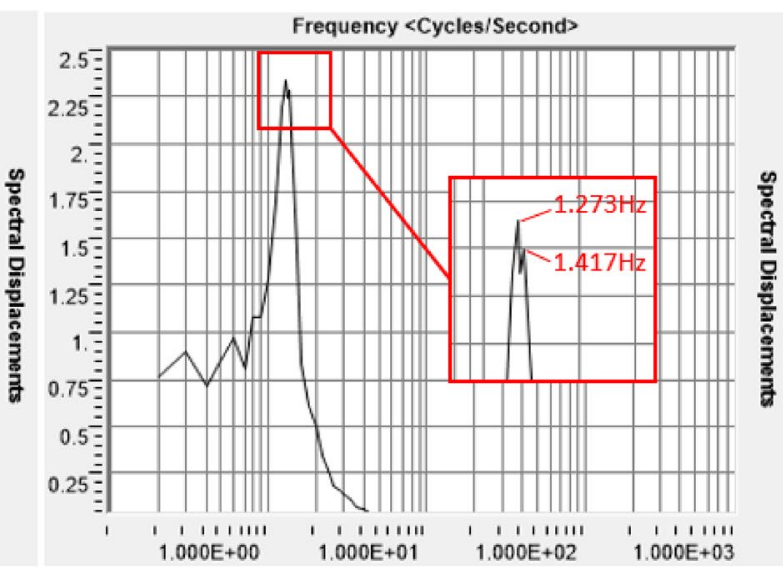

b

Fig. 24 Spectral displacement curves of N18 in the: a depth direction, b width direction (X axis: Hz, Y axis: mm) 
pressure, the wind vibration coefficient $\beta_{d}$ (time-series coefficient) is calculated as:

$$
\beta_{d}=1+\frac{U_{d}}{U_{s}},
$$

where $U_{d}$ is the maximum dynamic displacement of a point and $U_{s}$ is the static displacement under the average wind pressure.

In the load code, the wind vibration coefficient $\beta_{z}$ (code coefficient) is expressed by many factors and can be calculated as:

$$
\beta_{z}=1+\frac{\xi v \varphi_{z}}{\mu_{z}},
$$

where $\xi=1.51$, which is the fluctuating amplifying coefficient. $v=0.46$, which is the fluctuating influence coefficient. $\varphi_{z}$ is the modal coefficient at height $z \cdot \mu_{z}=1.0$, which is the height variation coefficient. All these coefficient values can be obtained from the load code.

The comparison of the time-series coefficients and the code coefficients is shown in Table 4.

The results show that the time-series coefficients are obviously higher than the code coefficients. If the code coefficient is used in the traditional hall-style timber building, the influence of the fluctuating wind on the structure will be underestimated. The time-series coefficients are 1.39-1.82 times the code coefficients, and the times decrease with increasing height because the load code aims at high-rise structures whose shapes and masses change uniformly with height. The vibration modes of high-rise buildings are discrete, and the degree of contribution of the first vibration mode is large. In the load code, only the first vibration mode is considered in calculating the modal coefficient, while the other

\begin{tabular}{|c|c|c|c|c|c|c|c|}
\hline$z / H$ & Point & $U d+U s(\mathrm{~mm})$ & Us (mm) & $\beta d$ & $\varphi z$ & $\beta z$ & $\beta d / \beta z$ \\
\hline 0.5 & N1 & 5.97 & 2.61 & 2.29 & 0.38 & 1.26 & 1.82 \\
\hline 0.5 & $\mathrm{~N} 2$ & 7.83 & 3.41 & 2.30 & 0.38 & 1.26 & 1.82 \\
\hline 0.5 & N3 & 5.90 & 2.61 & 2.26 & 0.38 & 1.26 & 1.80 \\
\hline 0.5 & N4 & 5.90 & 2.61 & 2.26 & 0.38 & 1.26 & 1.80 \\
\hline 0.5 & N5 & 5.90 & 2.61 & 2.26 & 0.38 & 1.26 & 1.80 \\
\hline 0.5 & N6 & 7.74 & 3.40 & 2.28 & 0.38 & 1.26 & 1.81 \\
\hline 0.5 & N7 & 6.05 & 2.67 & 2.27 & 0.38 & 1.26 & 1.80 \\
\hline 0.5 & N8 & 6.06 & 2.67 & 2.27 & 0.38 & 1.26 & 1.80 \\
\hline 0.7 & N9 & 6.80 & 3.19 & 2.14 & 0.67 & 1.46 & 1.46 \\
\hline 0.7 & N10 & 7.86 & 3.47 & 2.27 & 0.67 & 1.46 & 1.55 \\
\hline 0.7 & N11 & 6.85 & 3.19 & 2.14 & 0.67 & 1.46 & 1.47 \\
\hline 0.7 & $\mathrm{~N} 12$ & 6.85 & 3.19 & 2.15 & 0.67 & 1.46 & 1.47 \\
\hline 0.7 & N13 & 6.86 & 3.20 & 2.14 & 0.67 & 1.46 & 1.47 \\
\hline 0.7 & N14 & 7.72 & 3.51 & 2.20 & 0.67 & 1.46 & 1.51 \\
\hline 0.7 & N15 & 6.86 & 3.20 & 2.14 & 0.67 & 1.46 & 1.47 \\
\hline 0.7 & N16 & 6.85 & 3.20 & 2.14 & 0.67 & 1.46 & 1.46 \\
\hline 0.8 & N17 & 7.06 & 3.24 & 2.18 & 0.74 & 1.51 & 1.44 \\
\hline 0.8 & N18 & 8.25 & 3.93 & 2.10 & 0.74 & 1.51 & 1.39 \\
\hline 0.8 & N19 & 7.21 & 3.38 & 2.13 & 0.74 & 1.51 & 1.41 \\
\hline 0.8 & $\mathrm{~N} 20$ & 7.20 & 3.28 & 2.19 & 0.74 & 1.51 & 1.45 \\
\hline 0.8 & N21 & 7.27 & 3.31 & 2.19 & 0.74 & 1.51 & 1.45 \\
\hline 0.8 & N22 & 8.84 & 4.17 & 2.12 & 0.74 & 1.51 & 1.40 \\
\hline 0.8 & $\mathrm{~N} 23$ & 7.23 & 3.28 & 2.20 & 0.74 & 1.51 & 1.46 \\
\hline 0.8 & N24 & 7.22 & 3.26 & 2.21 & 0.74 & 1.51 & 1.46 \\
\hline 0.9 & N25 & 8.34 & 3.97 & 2.10 & 0.74 & 1.51 & 1.39 \\
\hline 0.9 & N26 & 8.40 & 3.97 & 2.12 & 0.74 & 1.51 & 1.40 \\
\hline 1 & N27 & 7.21 & 3.24 & 2.22 & 0.74 & 1.51 & 1.47 \\
\hline 1 & N28 & 8.41 & 3.84 & 2.19 & 0.74 & 1.51 & 1.45 \\
\hline 1 & N29 & 7.12 & 3.24 & 2.19 & 0.74 & 1.51 & 1.45 \\
\hline
\end{tabular}

Table 4 Comparison of the two wind vibration coefficients 
modes are all ignored. For structures similar to the main hall of the Tianning Temple, which is low-rise and flexible, the low-order natural frequencies are denser, so the time-series coefficients have no obvious change along the building height. In summary, the code coefficients are generally small and not applicable for early Chinese hallstyle timber buildings.

\section{Conclusions}

In this study, the main hall of the Tianning Temple was considered a representative of an early Chinese hall-style timber building to conduct the study of wind-induced performance. The wind pressure coefficients were determined via CFD simulation. The time-series wind pressures were generated, and the wind-induced vibration performance was analyzed by FEM. Some conclusions were drawn as follows.

(1) Under the two wind directions, the wind pressure coefficients are distributed symmetrically. Positive wind pressure occurs mainly at the windward surfaces, and negative wind pressure occurs mainly at the crosswind and leeward surfaces. The closer the area is to the edge, the denser the contour lines are, indicating that the change gradient of the wind pressure is larger in the area near the edges.

(2) Under the two wind directions, the maximum negative wind pressure occurs at the eave corners, and the coefficient is larger than 2, which means that the eave corners bear very large wind suction, providing an important explanation for why the corner beams of early Chinese hall-style timber buildings were designed to be very strong.

(3) The maximum positive wind pressure coefficient occurs at the central area of the windward pediment when $\theta=90^{\circ}$. The coefficients are generally larger than 1 . This value also explains why in most important gable-and-hip roof timber buildings built since the Song Dynasty, there is always a timber wind deflector set in front of the pediment for buffering the intense wind impact.

(4) The first mode shape of the main hall is the horizontal depth-direction vibration, the second is the horizontal width-direction vibration, and the third is the torsional vibration. The depth-direction lateral stiffness is smaller than the width-direction stiffness.

(5) The level of the wind loads in the middle of the windward roof is above average, and it is also the place where the large displacement occurs, whereas the maximum value is still within the allowable range.
(6) The structural response is influenced largely by the top three vibration modes, and the vibration modes after the third contribute little to the whole structural response.

(7) The time-series coefficients are 1.39-1.82 times larger than the code coefficients. Therefore, the wind-resistance calculation for timber buildings similar to the main hall of the Tianning Temple tends to be unsafe if the wind vibration coefficients are adopted based on the load code.

\section{Abbreviations}

CFD: Computational fluid dynamics; AR: Auto-regressive; FEM: Finite-element method; LES: Large eddy simulation; RANS: Reynolds-averaged Navier-Stokes; SST: Shear stress transfer; RNG: Re-normalization group; UDF: User-defined function.

\section{Acknowledgements}

Not applicable.

\section{Authors' contributions}

YH contributed to the methodology, simulation, results analysis and original draft of this manuscript. QC contributed to the methodology and review of this manuscript. All the authors contributed to the scanning and surveying of the temple. All authors read and approved the final manuscript.

\section{Funding}

This study was supported by the National Natural Science Foundation of China (Grant 51578127 \& 51778122).

\section{Availability of data and materials}

All data generated or analyzed during this study are included in this published article.

\section{Competing interests}

The authors declare that they have no competing interests.

Received: 20 June 2020 Accepted: 25 December 2020

Published online: 07 January 2021

\section{References}

1. National Cultural Heritage Administration. $(2019,10)$ The eighth branch of the major historical and cultural sites protected at the national level in China: http://www.ncha.gov.cn/art/2019/10/18/art_2289_157100.html. Accessed 23 Dec 2020

2. UNESCO (n.d.) World heritage list. Official Website of UNESCO: http://whc. unesco.org/en/list/. Accessed 23 Dec 2020

3. Wu DL, Wang JH, Feng YR, Wu ZZ, Zhang CX (1991) Experimental study on wind-induced characteristics of tall wooden towers in China. J Chongqing Univ 01:15-21 (In Chinese)

4. Li TY, Zhang SY, Li SW (2003) Vibration of Yingxian wooden tower under the action of wind. Mech Eng 25(2):40-42 (In Chinese)

5. Han YD, Chun Q (2017) Research on wind-induced response of the main hall of Baoguo temple. Sci Conserv Archaeol 29(6):84-94 (In Chinese)

6. Liu HR (2014) Research on shape factor of wind load of Taihe palace constructed with double-hipped roof in Qing dynasty. Dissertation, Changan University. (In Chinese)

7. Yang S H (2013) The numerical wind tunnel simulation of the wind load shape coefficient for the ancient buildings of Tang dynasty. Dissertation, Changan University. (In Chinese) 
8. Hanazato T, Minowa C, Niitsu Y, Nitto K, Kawai N, Maekawa H, Morri M (2010) Seismic and wind performance of five-storied pagoda of timber heritage structure. Adv Mater Res 133-134:79-95

9. Zisis I (2006) Structural monitoring and wind tunnel studies of a low wooden building. Dissertation, Concordia University.

10. Malone BP, Miller TH, Gupta R (2014) Gravity and wind load path analysis of a light-frame and a traditional timber frame building. J Archit Eng 20(4):B4013001

11. Morrison MJ, Henderson D, Kopp GA (2012) The response of a woodframe, gable roof to fluctuating wind loads. Eng Struct 41:498-509

12. He J, Pan F, Cai CS, Habte F, Chowdhury AG (2018) Finite-element modeling framework for predicting realistic responses of light-frame low-rise buildings under wind loads. Eng Struct 164:53-69

13. Razavi A, Sarkar PP (2018) Tornado-induced wind loads on a low-rise building: Influence of swirl ratio, translation speed and building parameters. Eng Struct 167:1-12

14. Singh J, Roy AK (2019) Effects of roof slope and wind direction on wind pressure distribution on the roof of a square plan pyramidal low-rise building using CFD simulation. Int J Adv Struct Eng 11(2):231-254

15. Roy A, Singh J, Sharma S, Verma S (2018) Wind pressure variation on pyramidal roof of rectangular and pentagonal plan low rise building through CFD simulation. Paper presented at the international conference on advances in construction materials and structures. Uttarakhand, India, 7-8 March 2018.

16. China Association for Engineering Construction Standardization (2012) Load code for the design of building structures GB50009-2012. China Architecture and Building Press, Beijing (In Chinese)

17. Xing FD, Mohotti D, Chauhan K (2018) Study on localised wind pressure development in gable roof buildings Thaving different roof pitches with experiments, RANS and LES simulation models. Build Environ 143:240-257

18. Kim YC, Tamura Y (2015) Simulation of Wind Pressures on a Target LowRise Building in Large Group by RANS Turbulence Model. J Aerosp Eng 28(3):04014082

19. Stathopoulos T, Zhou YS (1993) Numerical simulation of wind-induced pressures on buildings of various geometries. J Wind Eng Indus Aerosp 46-57:419-430

20. Juan MG, Facundo B (2019) Optimization of RANS turbulence models using genetic algorithms to improve the prediction of wind pressure coefficients on low-rise buildings. J Wind Eng Indus Aerosp 193:103978
21. Tominaga Y, Stathopoulos T (2017) Steady and unsteady RANS simulations of pollutant dispersion around isolated cubical buildings: effect of large-scale fluctuations on the concentration field. J Wind Eng Indus Aerosp 165:23-33

22. Franke J, Hellsten A, Schlunzen KH, Carissimo B (2011) The cost 732 best practice guideline for CFD simulation of flows in the urban environment: a summary. Int J Environ Pollut 44:419-427

23. Tominaga Y, Mochida A, Yoshie R, Kataoka H, Nozu T, Yoshikawa M, Shirasawa T (2008) AIJ guidelines for practical applications of CFD to pedestrian wind environment around buildings. J Wind Eng Ind Aerod 96(10):1749-1761

24. Chun Q, Pan JW, Dong YH (2016) Mechanical properties of Tou mortisetenon joints of the traditional timber buildings in the south Yangtze river regions. J Southwest Jiaotong Univ 51(5):862-869 (In Chineses)

25. Chun Q, Jin H, Dong YH, Hua YW, Han YD (2019) Research on mechanical properties of Dingtougong mortise-tenon joints of Chinese traditional hall-style timber buildings built in the Song and Yuan dynasties. Int J Archit Herit 35:235-250

26. Liu Y, Yang J (2007) Structural analysis and modeling simplification of Liao-dynasty structures in Dule temple. J Southeast Univ 37(5):887-891 (In Chinese)

27. Ding S (2014) Timber construction in the main hall of Tianning Temple of Jinhua. Dissertation, Southeast University. (In Chinese)

28. China Southeast Architectural Design and Research Institute Corp. Ltd (2003) Code for design of timber structures GB50005-2003. China Planning Press, Beijing (In Chinese)

29. Sichuan Institute of Building Research (2020) Chinese technical code for maintenance and strengthening of ancient timber buildings GB/ T50165-2020. Architectural Industry Press, Beijing (In Chinese)

30. Zhang XT (1985) Calculation of structural wind pressure and wind vibration. Tongji University Press, Shanghai (In Chinese)

\section{Publisher's Note}

Springer Nature remains neutral with regard to jurisdictional claims in published maps and institutional affiliations.

\section{Submit your manuscript to a SpringerOpen ${ }^{\circ}$ journal and benefit from:}

- Convenient online submission

- Rigorous peer review

- Open access: articles freely available online

- High visibility within the field

Retaining the copyright to your article

Submit your next manuscript at $\boldsymbol{\nabla}$ springeropen.com 